\title{
In air synthesis of Psy-cl-poly(AAm) network and its application in water-absorption from oil-water emulsions
}

\author{
B. S. Kaith*, K. Kumar \\ Department of Applied Sciences, National Institute of Technology (Deemed University), Hamirpur 177005 (H. P.), India
}

Received 5 April 2007; accepted in revised form 6 June 2007

\begin{abstract}
In this current investigation psyllium has been functionalized with acrylamide in the presence of potassium persulphate (KPS)-hexamethylene tetramine (HMTA) as an initiator-crosslinker system. After the initial optimization of different reaction parameters the resultant hydrogel was used for the absorption of water from different water-oil emulsions as a function of time, temperature, $\mathrm{pH}$ and $\mathrm{NaCl}$ concentration. $4216 \%$ of water absorption with $4 \cdot 279 \cdot 10^{-2}$ mol $\cdot 1^{-1} \mathrm{HMTA}$ concentration has been observed.
\end{abstract}

Keywords: biopolymers, psyllium, acrylamide, water absorption, water-oil emulsions

\section{Introduction}

These days modified polysaccharides have been the major area of scientific research. These polysaccharides being cost effective, biodegradable and quite efficient towards various technological processes, provides a better option for the artificial synthetic materials. Lot of work has been carried-out on various polysaccharides such as starch [1], cellulose [2], chitosan [3], dextrin [4], guar-gum [5], psyllium [6] and many more. The end products obtained were found to be the quality products as they were efficiently used in different technological processes viz. drug- delivery [7, 8], agriculture [9, 10] (insecticide and pesticide delivery), water treatment [11] (removal of toxic metal ions from wastewater and flocculation) and membrane technology [12].

Psyllium is mucilage forming natural polysaccharide, mainly known for its medicinal value. Chemically, psyllium husk is composed of arabinoxylan [13], which is complex polysaccharide having linearly joined $\beta$-1,4-linked D-xylopyranose units with side branches of $\alpha$-L-arabinofuranose residues
[14]. Mishra et al. have modified psyllium for its use in flocculation [15-22]. They found that the modified polymer was very efficient flocculent for the removal of toxic effluents from sewage, tannery and textile waste-water.

In the present study psyllium has been modified through grafting with acrylamide using potassium persulphate-hexamethylene tetramine as the initiator-crosslinker system. The synthesized polymer has been used for the selective absorption of water from different water-oil emulsions.

\section{Experimental}

\subsection{Materials and method}

Psyllium 'Psy' (Sidhpur Sat-Isabgol Factory, Gujarat), acrylamide 'AAm' (LOBA Chemie Pvt. Ltd., Mumbai), potassium per sulphate 'KPS' (SD Fine, Mumbai) and hexamethylene tetramine 'HMTA' (LOBA Chemie Pvt. Ltd., Mumbai) were used as received.

Pellets of the samples with $\mathrm{KBr}$ for FTIR studies were prepared in hydraulic press and the spectra

*Corresponding author, e-mail: kaith@nitham.ac.in

(C) BME-PT and GTE 
were recorded using Perkin Elmer spectrophotometer, weighing was done on electronic balance (LIBROR AEG-220, Shimadzu). SEMs of the samples were taken on Jeol Steroscan 150 Microscope. For this the gels were gold plated to have a conducting impact. Scanning was synchronized with microscopic beam in order to maintain the small size over large distance relative to the specimen. The resulting images had a great depth of the field. A remarkable three dimensional appearance with high resolution was obtained. TGA/DTA studies were carried-out on Leinesis thermal analyzer in air at a heating rate of $10^{\circ} \mathrm{C} / \mathrm{min}$. with $6.0 \mathrm{mg}$ of the dried sample.

\subsection{Preparation of sample}

Psyllium was modified with acrylamide using potassium persulphate-hexamethylene tetramine as an initiator-crosslinker system. Initially different reaction conditions were optimized by varying various reaction parameters, such as initiator concentration, amount of solvent, reaction time, reaction temperature, $\mathrm{pH}$ of the reaction medium, monomer concentration and crosslinker concentration, so as to get the optimized graft copolymer. Psyllium $(1 \mathrm{~g})$ was taken in a beaker and added known volume of solvent. Added known amount of initiator dissolved previously in minimum amount of solvent to the solution followed by the addition of known weight of monomer. Stir the solution till uniform mixture was obtained. The mixture was then put under required reaction conditions i. e. temperature, $\mathrm{pH}$ etc. for the reaction to proceed. The percent grafting $P_{g}$ was calculated as per the method reported earlier [23].

Psy-cl-poly(AAm) in-air was synthesized using hexamethylene tetramine as a crosslinker. The same procedure mentioned above was followed with the addition of known weight of crosslinker, dissolved previously in minimum volume of solvent, after the addition of monomer. Optimization was carried-out with respect to percent swelling $\left(P_{s}\right)$ by varying the monomer and crosslinker concentrations. The optimized hydrogel was taken for further studies.

The graft copolymer was extracted from the reaction mixture by stirring the reaction mixture in acetone for 5-6 hours, so that the homopolymer got completely removed from the reaction mixture.

\subsection{Water absorption studies in oil-water emulsion}

Water absorption has been carried out by immersing $100 \mathrm{mg}$ each of the gel directly in petrol-water, diesel-water, kerosene-water and petroleum etherwater emulsions $(80 \mathrm{ml}$ each) at different time $(04$, $08,12,16$ and $24 \mathrm{hrs})$ and temperatures $(25,30,35$, 40,45 and $50^{\circ} \mathrm{C}$ ). Tween- 20 was added as an emulsifying agent which is $10 \%$ of the total solution. Variation of $\mathrm{pH}$ (acidic, neutral and alkaline) and $\mathrm{NaCl}$ concentration $(1 \%, 5 \%, 10 \%$ and $15 \%)$ has also been done at optimum time and temperature obtained. Percent swelling $\left(P_{s}\right)$ was calculated using earlier documented relation [24].

\section{Results and discussion}

The mucilage forming fraction (arabinoxylan) of psyllium bears hydroxyl groups that are the active sites for the graft co-polymerization of poly(AAm) onto it and can be shown through mechanism already reported for synthesis in vacuum [25].

\subsection{Optimization of different reaction parameters}

Variation of initiator concentration showed an increase of percent grafting $\left(P_{g}\right)$ with the increase in initiator concentration upto $0.9 \cdot 10^{-2} \mathrm{~mol} \cdot \mathrm{l}^{-1}$ and a decrease thereafter (Figure 1a). This is due to the predominance of homo-polymerization over copolymerization at higher initiator concentration.

Amount of solvent showed a clear effect on the $P_{g}$ with maximum (147\%) in $25 \mathrm{ml}$ solvent. This might be due to increase in the concentration of the ${ }^{*} \mathrm{OH}$ as per the following reaction:

$\mathrm{SO}_{4}^{-*}+\mathrm{H}_{2} \mathrm{O} \rightarrow \mathrm{HSO}_{4}^{-}+{ }^{*} \mathrm{OH}$

The sulphate ion radical formed from homolytic cleavage of initiator reacts with water and give rise to hydroxyl free radical [25].

However, thereafter a decreasing trend was observed (Figure 1b), which might be due to the termination reaction:

Psy-O- $(\mathrm{M})_{\mathrm{n}}-\mathrm{M}^{*}+{ }^{*} \mathrm{OH} \rightarrow$ Psy-O-(M) $)_{\mathrm{n}+1}-\mathrm{OH}$

where, Psy - psyllium, M - monomer, ${ }^{*}$ - free radical. 
a)

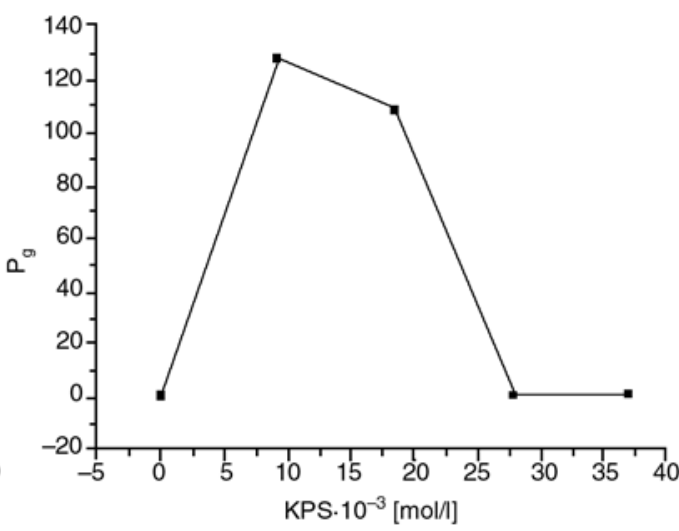

b)

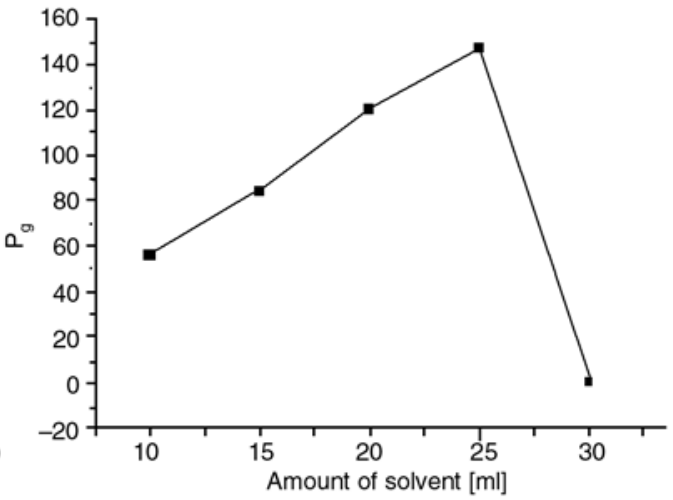

c)

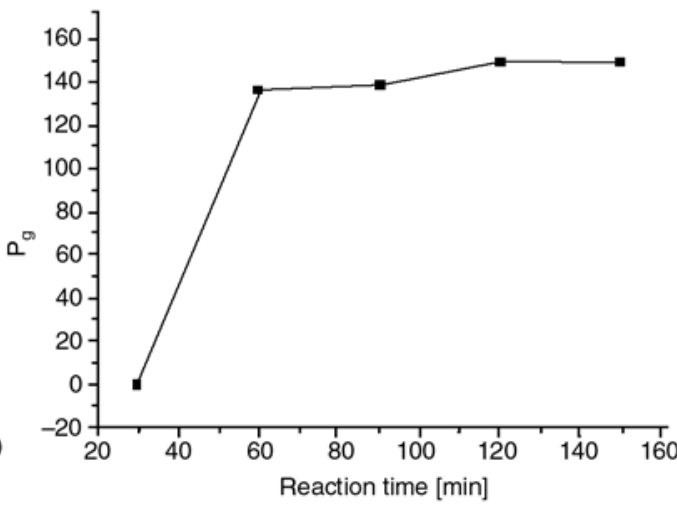

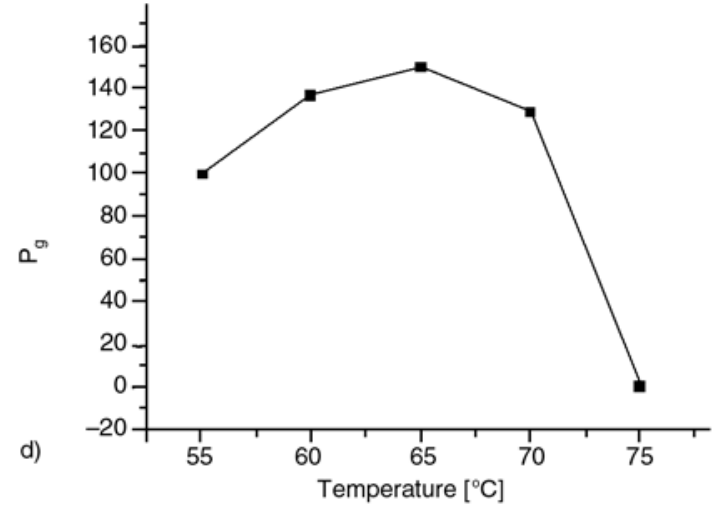
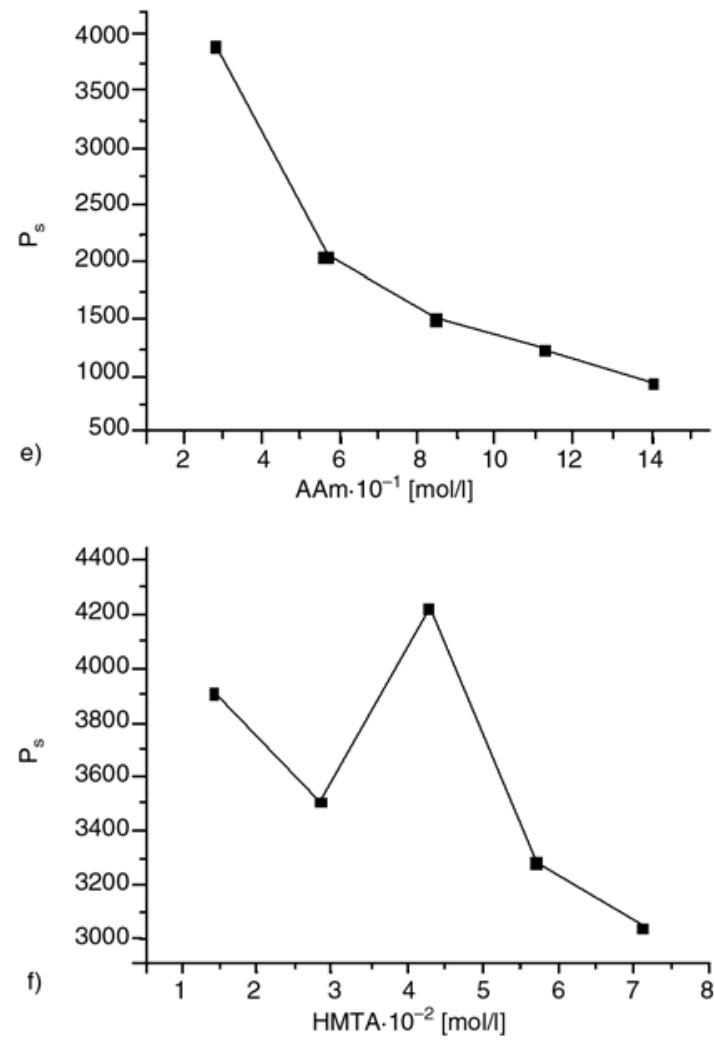

Figure 1. a) Effect of initiator concentration onto percent grafting $\left(P_{g}\right)$. [AAm $]=0.703 \mathrm{~mol} \mathrm{l}^{-1}$, Psyllium $=1 \mathrm{~g}$, reaction time $=2 \mathrm{~h}$, reaction temperature $=65^{\circ} \mathrm{C}$.

b) Effect of amount of solvent on to percent grafting $\left(P_{g}\right)$. [AAm $]=0.703 \mathrm{~mol} \mathrm{l}^{-1},[\mathrm{KPS}]=0.00924 \mathrm{~mol} \mathrm{l}^{-1}$, Psyllium $=1 \mathrm{~g}$, reaction time $=2 \mathrm{~h}$, reaction temperature $=65^{\circ} \mathrm{C}$.

c) Effect of reaction time on to percent grafting $\left(P_{g}\right)$. $[\mathrm{AAm}]=0.703 \mathrm{~mol} \mathrm{l}^{-1}$, $[\mathrm{KPS}]=0.00924 \mathrm{~mol} \mathrm{l}^{-1}$, Psyllium $=1 \mathrm{~g}$, reaction temperature $=65^{\circ} \mathrm{C}$.

d) Effect of temperature onto percent grafting (Pg). $[\mathrm{AAm}]=0.703 \mathrm{~mol} \mathrm{l}^{-1}$, [KPS $]=0.00924 \mathrm{~mol} \mathrm{l}^{-1}$, Psyllium $=1 \mathrm{~g}$, reaction time $=2 \mathrm{~h}$.

e) Effect of AAm concentration onto percent swelling $\left(P_{s}\right)$. [KPS] $=0.00924 \mathrm{~mol} \mathrm{l}^{-1}$, Psyllium $=1 \mathrm{~g}, \mathrm{pH}=7.0$, [HMTA $]=.01426 \mathrm{~mol} \mathrm{l}^{-1}$, reaction time $=2 \mathrm{~h}$, reaction temperature $=65^{\circ} \mathrm{C}$.

f) Effect of crosslinker concentration onto percent swelling $\left(P_{s}\right)$. [AAm $]=0.2812 \mathrm{~mol} \mathrm{l}^{-1}$, [KPS] $0.00924 \mathrm{~mol} \mathrm{l}^{-1}$, Psyllium $=1 \mathrm{~g}$, reaction time $=2 \mathrm{~h}$, reaction temperature $=65^{\circ} \mathrm{C}$.

$P_{g}$ was found to increase with increase in reaction time and temperature reaching maximum (149\%) at 120 minutes and $65^{\circ} \mathrm{C}$ and thereafter it decreased (Figures 1c, 1d). This may be due to the fact that with increase in reaction time and temperature, the active sites for the copolymerization decrease resulting in the predominance of homo-polymerization.

It was found with the variation of $\mathrm{pH}$ that polymerization reaction takes only in distilled water (neu- 
tral medium) and fails to occur in $0.5 \mathrm{~N} \mathrm{NaOH}$ (alkaline medium) and $0.5 \mathrm{~N} \mathrm{HCl}$ (acidic medium), since, the backbone polymer is not stable under these conditions and uniform solution was not formed during synthesis.

The resultant optimized Psy-g-poly(AAm) in-air was further subjected to network formation using hexamethylene tetramine as the crosslinker. The polymer was optimized for its monomer as well as crosslinker concentration with respect to $P_{s}$. Maximum $P_{s}(3900 \%)$ for the monomer variation was found to be with $2.8 \cdot 10^{-1} \mathrm{~mol} \cdot \mathrm{l}^{-1}$ monomer concentration and $4216 \%$ with $4.3 \cdot 10^{-2} \mathrm{~mol} \cdot \mathrm{l}^{-1}$ crosslinker concentration. Beyond these concentrations, $P_{s}$ was found to decrease. This can be explained on the basis that with increase in monomer as well as the crosslinker concentration, the crosslinking density in the gels increases resulting in lesser approachability of the solvent towards the matrix, hence lesser swelling (Figures 1e, 1f). The polymers below $2.8 \cdot 10^{-1} \mathrm{~mol} \cdot \mathrm{l}^{-1}$ monomer concentration were not formed.

\subsection{FTIR spectroscopy}

Broad peaks are obtained in the IR spectrum of psyllium at $3780.9 \mathrm{~cm}^{-1}$ and $3427.6 \mathrm{~cm}^{-1}(\mathrm{O}-\mathrm{H}$ stretching bonded absorption of carbohydrates), $2925.8 \mathrm{~cm}^{-1} \quad\left(\mathrm{CH}_{2}\right.$ asymmetric stretching $)$, $1378.8 \mathrm{~cm}^{-1}\left(\mathrm{CH}, \mathrm{CH}_{2}\right.$ and $\mathrm{OH}$ in-plane bending in carbohydrates), $1039.5 \mathrm{~cm}^{-1} \quad(\mathrm{C}-\mathrm{O}$ stretching region as complex bands, resulting from $\mathrm{C}-\mathrm{O}$ and C-O-C stretching vibrations), $897 \mathrm{~cm}^{-1}$ and $533 \mathrm{~cm}^{-1}$ (pyranose rings).

On the other hand, IR spectrum of Psy-cl-poly (AAm) in-air showed peaks at $1666.7 \mathrm{~cm}^{-1}(\mathrm{C}=\mathrm{O}$

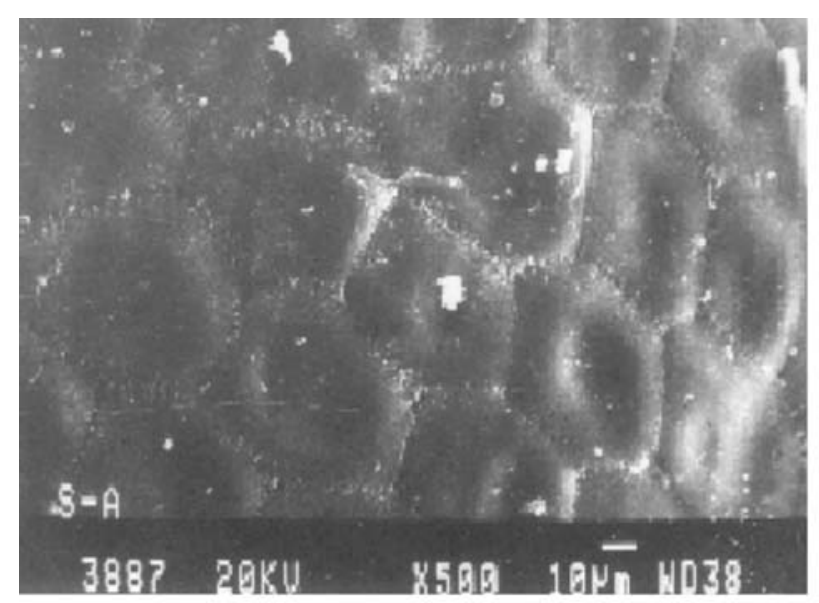

a)
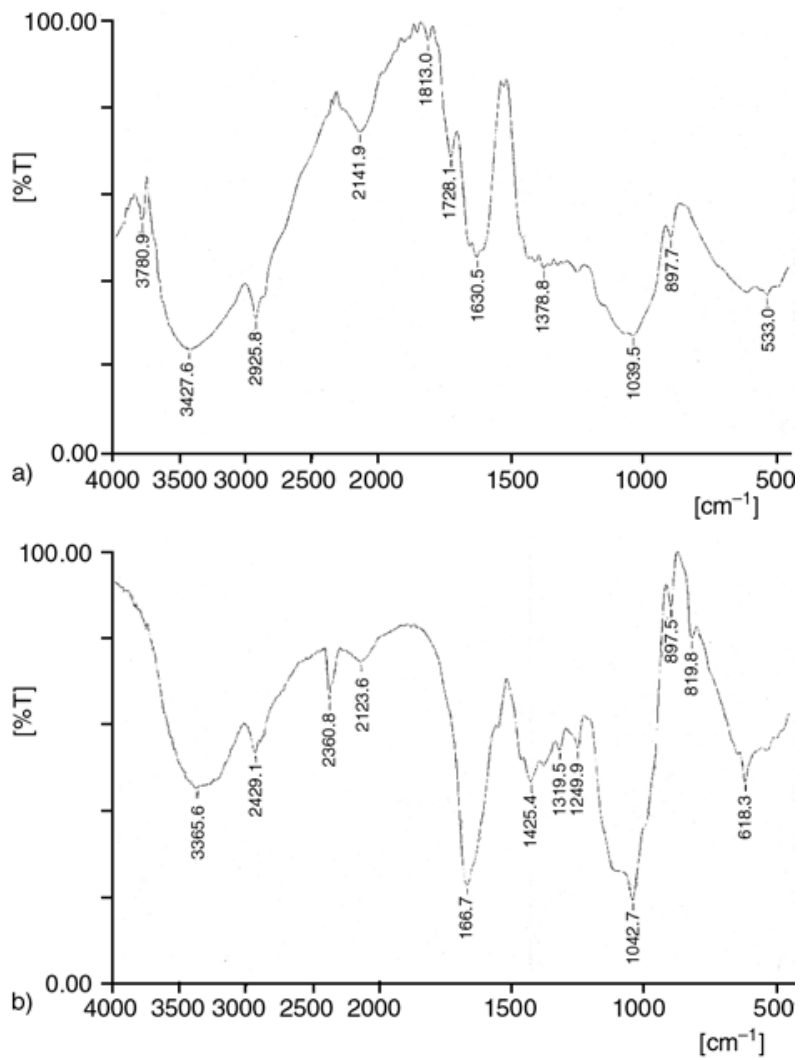

Figure 2. a)FTIR spectrum of Psyllium, b)FTIR spectrum of Psy-cl-poly(AAm) in-air

stretching of Amide I band), $1425.4 \mathrm{~cm}^{-1}$ (N-H inplane bending of Amide II band), $1249.9 \mathrm{~cm}^{-1}$ (C-N stretching vibrations of Amide III band) and $819.3 \mathrm{~cm}^{-1}$ (OCN deformations of Amide IV band), besides peaks obtained with that of psyllium (Figures 2a, 2b).

\subsection{Scanning electron microscopy}

Intricacies brought about by the graft co-polymerization and crosslinking were clearly illustrated by

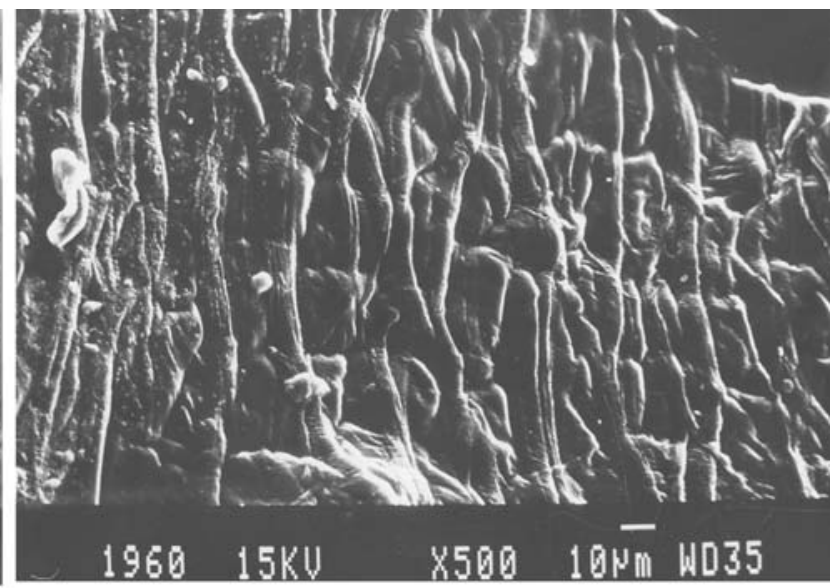

Figure 3. a) SEM of Psyllium, b) SEM of Psy-cl-poly(AAm) in-air 
the SEM results of psyllium and Psy-cl-poly(AAm) in-air. The morphological changes in the features of psyllium after grafting and networking are quite evident (Figures 3a, 3b).

\subsection{Thermal behavior of the gels}

Thermo-gravimetric analysis of both psyllium and Psy-cl-poly(AAm) in-air was carried-out as a function of percent weight loss versus temperature. It has been found that in case of psyllium, initial decomposition temperature $\left(229.3^{\circ} \mathrm{C}\right)$ is higher as compared to that of Psy-cl-poly(AAm) in-air $\left(214.0^{\circ} \mathrm{C}\right)$. This appears due to initial disturbance in the crystalline lattice of the backbone during graft co-polymerization. However, final decomposition temperature of Psy-cl-poly(AAm) in-air has been found to be higher $\left(624.3^{\circ} \mathrm{C}\right)$ than that of psyllium $\left(601.9^{\circ} \mathrm{C}\right)$. This shows that on crosslinking of psyllium with AAm-HMTA, it becomes thermally more stable. In both the cases, two-stage decomposition has been observed (Figures 4a, 4b). The
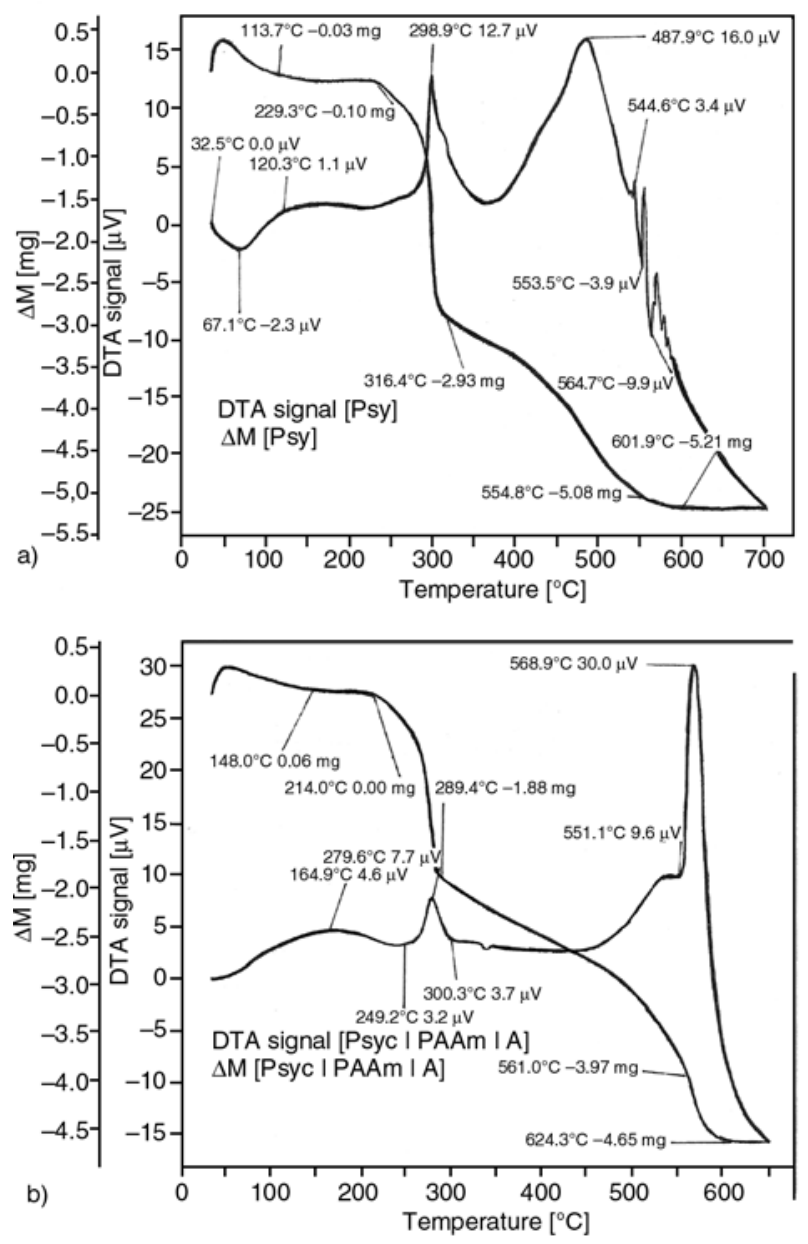

Figure 4. a) DTA-TG curves of Psyllium, b) DTA-TG curves of Psy-cl-poly(AAm) in-air results are further supported with DTA studies. In case of psyllium one endothermic peak at $67.1^{\circ} \mathrm{C}$ $(-2.3 \mu \mathrm{V})$ and two exothermic peaks at $298.9^{\circ} \mathrm{C}$ $(12.7 \mu \mathrm{V})$ and $487.9^{\circ} \mathrm{C}(16.0 \mu \mathrm{V})$ have been observed. Whereas in case of Psy-cl-poly(AAm) in-air, two exothermic peaks at $279.6^{\circ} \mathrm{C}(7.7 \mu \mathrm{V})$ and $568.9^{\circ} \mathrm{C}(30.0 \mu \mathrm{V})$ have been found. It shows that exothermic combustion of Psy-cl-poly(AAm) in-air persists at higher temperature as compared to that of psyllium.

\subsection{Water uptake studies in oil-water emulsion}

\subsubsection{Effect of time}

Water uptake studies were carried out at different time intervals $(4,8,12,16$ and $24 \mathrm{hrs})$. It was found that with increase in time, $P_{s}$ increases but the rate of water-absorption slowed down after $12 \mathrm{hrs}$ and attained a constant value at $24 \mathrm{hrs}$ (Figure 5). It is due to the fact that after $24 \mathrm{hrs}$, the pores of the network structure got saturated with the solvent molecules thereby leaving no more space for further solvent entry into the matrix.

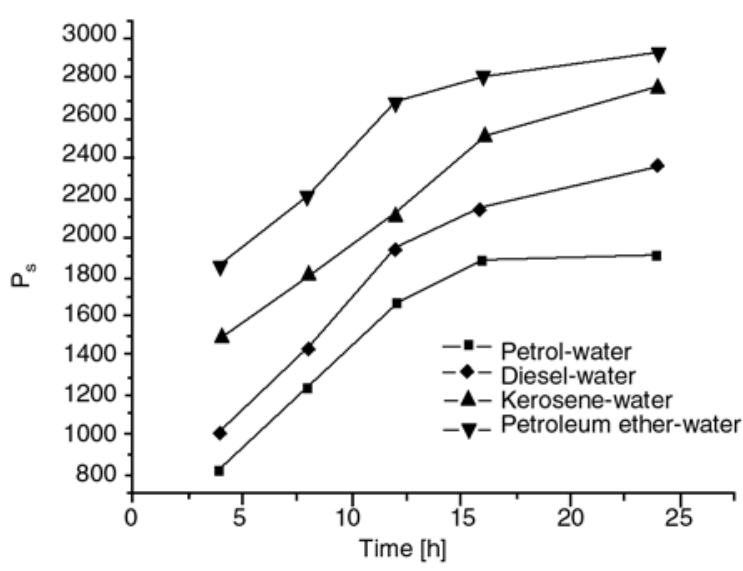

Figure 5. Effect of time onto percent swelling of Psy-clpoly(AAm) in different oil-water emulsions. $\left\{\left[\mathrm{AAm}=2.8 \cdot 10^{-1} \mathrm{~mol} \mathrm{l}^{-1},[\mathrm{HMTA}=\right.\right.$ $\left.4.3 \cdot 10^{-2} \mathrm{~mol} \mathrm{l}^{-1}\right\}$

\subsubsection{Effect of temperature}

Temperature of the swelling media was varied from 25 to $50^{\circ} \mathrm{C}$. Ps increases with increase in temperature upto $45^{\circ} \mathrm{C}$ and decreased thereafter in all the different oil-water emulsions (Figure 6). This might be due to the reason that at higher temperature, the polymer became compact leading to desorption. 


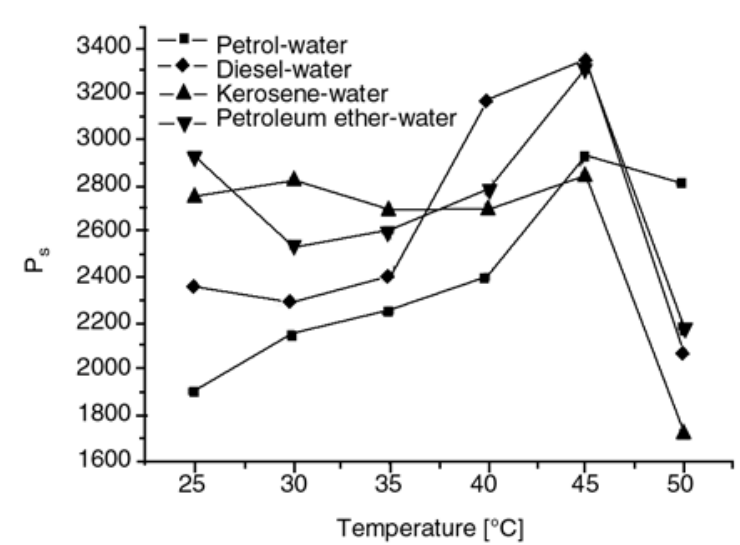

Figure 6. Effect of temperature on to percent swelling (Ps) of Psy-cl-poly(AAm) in different oil-water emulsions. $\left\{\left[\mathrm{AAm}=2.8 \cdot 10^{-1} \mathrm{~mol} \mathrm{1} \mathrm{l}^{-1},[\mathrm{HMTA}=\right.\right.$ $\left.4.3 \cdot 10^{-2} \mathrm{~mol} \mathrm{l}^{-1}\right\}$

\subsubsection{Effect of $\mathbf{p H}$}

Water uptake capacity of the polymer was also investigated in different $\mathrm{pH}$ media $(0.5 \mathrm{M} \mathrm{NaOH}$, distilled water and $0.5 \mathrm{M} \mathrm{HCl}$ ). The polymer got disintegrated both in alkaline and acidic media but showed appreciable $P_{s}$ in distilled water. It is due to the fact that since Psy-cl-poly(AAm) gels are not stable towards both acidic and basic media, so the network structure of the absorbent starts breaking and ultimately disintegrates [25].

\subsubsection{Effect of $(\mathrm{NaCl})$ onto percent swelling}

$\mathrm{NaCl}$ concentration of the swelling media was varied from $1 \%$ to $15 \%$. As is evident from Figure 7 , the $P_{s}$ increases with the increase in $\mathrm{NaCl}$ concentration upto $10 \%$ and afterwards a decreasing trend has been observed. The reason behind this is that in $\mathrm{NaCl}$ solution $\mathrm{Na}^{+}$ions got entrapped in the porous

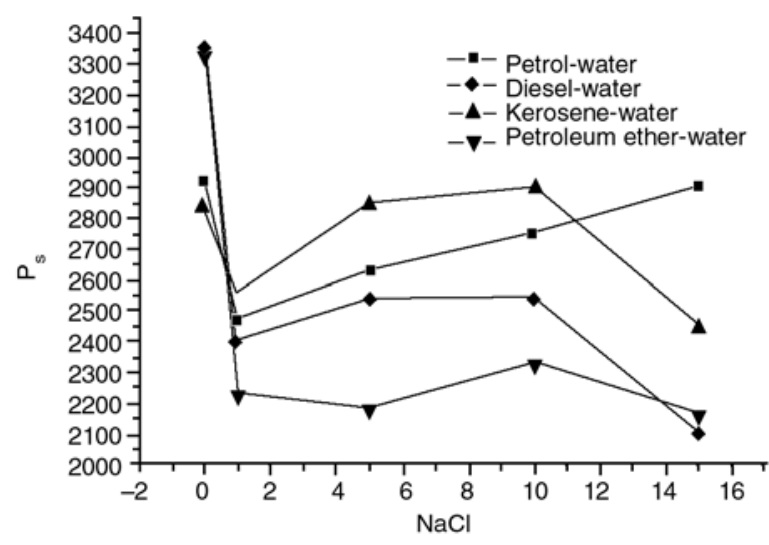

Figure 7. Effect of $\mathrm{NaCl}$ concentration on to percent swelling $\left(P_{s}\right)$ of Psy-cl-poly $(\mathrm{AAm})$ in different oil-water emulsions. $\left\{\left[\mathrm{AAm}=2.8 \cdot 10^{-1} \mathrm{~mol} \mathrm{l}^{-1}\right.\right.$, $\left[\right.$ HMTA $\left.=4.3 \cdot 10^{-2} \mathrm{~mol} \mathrm{l}^{-1}\right\}$ networks and being hydrophilic in nature causes more water absorption.

\section{Conclusions}

The foregoing discussion reveals that the modification of psyllium through copolymerization with acrylamide using potassium persulphate-hexamethylene tetramine as an initiator-crosslinker system has extended its applicability and improved its property profile. Here, the synthesized hydrogel showed enhanced thermal stability than that of psyllium. Moreover, the synthesized hydrogel showed temperature and $\mathrm{pH}$ dependent water specific absorption from different water-oil emulsions. The $\mathrm{pH}$ sensitive behavior makes the hydrogel a suitable candidate for polymeric drug delivery system. The hydrogel also behaved as a salt-resistant polymer as the absorption was more in case of $10 \%$ salt solution than $1 \%$ salt solution. The synthesized polymers are, therefore, important from technological view point.

\section{References}

[1] Lee J. S., Kumar R. N., Rozman H. D., Azemi B. M. N.: Pasting, swelling and solubility properties of UV initiated starch-graft-poly(AA). Food Chemistry, 91, 203-211 (2005).

[2] Kumar V., Bhardwaj Y. K., Rawat K. P., Sabharwal S.: Radiation-induced grafting of vinylbenzyltrimethylammonium chloride (VBT) onto cotton fabric and study of its anti-bacterial activities. Radiation Physics and Chemistry, 73, 175-182 (2005).

[3] Singh V., Tripathi D. N., Tiwari A., Sanghi R.: Microwave synthesized chitosan-graft-poly(methylmethacrylate): An efficient $\mathrm{Zn}^{2+}$ ion binder. Carbohydrate Polymers, 65, 35-41 (2006).

[4] Cohen E., Zilkha A.: Anionic graft polymerization of methyl methacrylate on starch and dextrin. Journal of Polymer Science Part A-1: Polymer Chemistry, 7, 1881-1892 (2003).

[5] Pandey P. K., Srivastava A., Tripathy J., Behari K.: Graft copolymerization of acrylic acid onto guar gum initiated by vanadium (V)-mercaptosuccinic acid redox pair. Carbohydrate Polymers, 65, 414-420 (2006).

[6] Mishra A., Bajpai M.: Flocculation behaviour of model textile wastewater treated with a food grade polysaccharide. Journal of Hazardous Materials, 118, 213-217 (2005).

[7] Kang G. D., Cheon S. H., Song S. C.: Controlled release of doxorubicin from thermosensitive poly(organophosphazene) hydrogels. International Journal of Pharmaceutics, 319, 29-36 (2006). 
[8] Kang G. D., Cheon S. H., Khang G., Song S. C.: Thermosensitive poly(organophosphazene) hydrogels for a controlled drug delivery. European Journal of Pharmaceutics and Biopharmaceutics, 63, 340-346 (2006).

[9] Rudzinski W. E., Dave A. M., Vaishnav U. H., Kumbar S. G., Kulkarni, A. R., Aminabhavi, T. M.: Hydrogels as controlled release devices in agriculture. Designed Monomers and Polymers, 5, 39-65 (2002).

[10] Rudzinski W. E., Chipuk T., Dave A. M., Kumbar S. G., Aminabhavi T. M.: pH-sensitive acrylic-based copolymeric hydrogels for the controlled release of a pesticide and a micronutrient. Journal of Applied Polymer Science, 87, 394-403 (2002).

[11] Okieimen F. E., Sogbaike C. E., Ebhoaye J. E.: Removal of cadmium and copper ions from aqueous solution with cellulose graft copolymers. Separation and Purification Technology, 44, 85-89 (2005).

[12] Huang J., Wang X-L., Yu X-H.: Solute permeation through the polyurethane-NIPAAm hydrogel membranes with various cross-linking densities. Desalination, 192, 125-131 (2006).

[13] Fischer M. H., Yu N., Gray G. R., Ralph J., Anderson L., Marlett J. A.: The gel-forming polysaccharide of psyllium husk (Plantago ovata Forsk). Carbohydrate Research, 339, 2009-2017 (2004).

[14] Izydorczyk M. S., Biliaderis C. G.: Cereal arabinoxylans: advances in structure and physicochemical properties[J]. Carbohyrate Polymers, 28, 33-48. (1995).

[15] Agarwal M., Srinivasan R., Mishra A.: Synthesis of plantago psyllium mucilage grafted polyacrylamide and its flocculation efficiency in tannery and domestic wastewater. Journal of Polymer Research, 9, 69-73 (2002).

[16] Mishra A., Agarwal M., Bajpai M., Rajani S., Mishra R. P.: Plantago psyllium mucilage for sewage and tannery effluent treatment. Iranian Polymer Journal, 11, 381-386 (2002).
[17] Mishra A., Srinivasan R., Bajpai M., Dubey R.: Use of polyacrylamide-grafted plantago psyllium mucilage as a flocculant for treatment of textile wastewater. Colloid and Polymer Science, 282, 722-727 (2004).

[18] Mishra A., Bajpai M.: Flocculation behaviour of model textile wastewater treated with a food grade polysaccharide. Journal of Hazardous Materials, 118 213-217 (2005).

[19] Mishra A., Srinivasan R., Dubey R.: Flocculation of textile wastewater by plantago psyllium mucilage. Macromolecular Materials and Engineering, 287, 592-596 (2002).

[20] Srinivasan R., Agarwal M., Mishra A.: Synthesis of plantago psyllium mucilage grafted polyacryloniyrile and its flocculation efficiency in textile effluent water. Quality Research Journal of Canada, 37, 371-378 (2002).

[21] Mishra A., Yadav A., Agarwal M., Srinivasan R.: Plantago psyllium-grafted-polyacrylonitrile: Synthesis, characterization and its use for solid removal from sewage wastewater. Chinese Journal of Polymer Science, 23, 113-118 (2004).

[22] Mishra A., Srinivasan R., Agarwal M., Dubey R.: P.psyllium-g-polyacrylamide: synthesis and characterization. Polymer Bulletin, 48, 439-444 (2002).

[23] Kaith B. S., Singha A. S., Sharma S. K.: Graft copolymerization of flax fibers with binary vinyl monomer mixtures and evaluation of swelling, moisture absorbance and thermal behaviour of the grafted fibers. Journal of Polymer Materials, 20, 195-159 (2003).

[24] Chauhan G. S., Kaur I., Misra B. N., Singha A. S., Kaith B. S.: Modification of natural polymers: graft copolymerization of methyl methacrylate onto rayon fiber initiated by ceric ions- a study in swelling and thermal properties. Journal of Polymer Materials, 16, 245-252 (1999).

[25] Kaith B. S., Kumar K.: In vacuum preparation of psycl-poly(aam) super-absorbent and its applications. in oil-industry. e-Polymers, 002, (2007). 